\title{
REVISTA
CRISULA
}

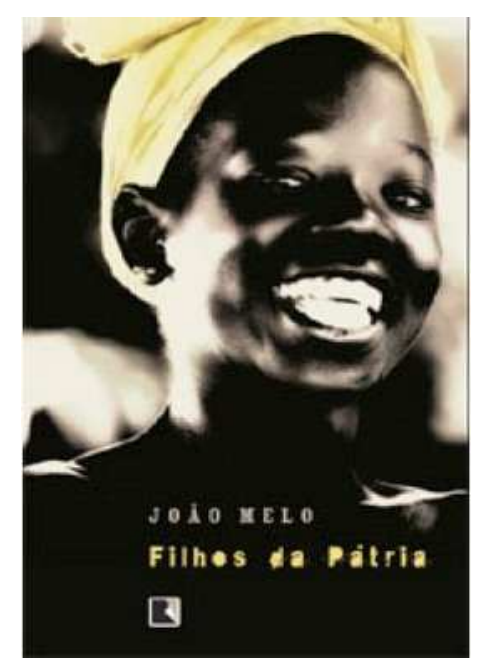

\section{Filhos da Pátria, de João Melo}

\author{
Emanuelle Rodrigues dos Santos ${ }^{1}$
}

De Angola, primeiramente publicado em 2001 pela editora Nzila, chega agora ao Brasil, através da editora Record, Filhos da Pátria, de João Melo. Um livro de contos que obriga a revisitação da historia literária daquele país e convida a um passo adiante nas discussões acerca de sua produção literária.

Embora ainda não possa ser considerada farta, já é rica a fortuna critica disponivel no Brasil acerca das Literaturas Africanas em Lingua Portuguesa, que investiga sua estreita relação com a constituição dessas nações em sua luta pela independência. No caso específico de Angola, a literatura desempenhou papel fundamental na criação de narrativas que servissem como cimento social aos "grupos étnicos historicamente diferenciados, integrados em universos culturais distintamente marcados" (CHAVES, 1999, p. 30) que formam o país.

\footnotetext{
Mestranda em Estudos Comparados de Literaturas de Língua Portuguesa, FFLCH/USP, com a pesquisa: A questão de identidade na ficção em prosa de João Melo. E-mail: emanuelle.santos@gmail.com
} 
A diversidade étnica de Angola é um contrassenso à própria gênese européia da idéia de nação. Como aprendemos nas lições de Raymond Williams, (1985, p. 214) nação é um termo cujo uso no ocidente data do século XIII e que designava antes um grupo racial que um grupo politicamente organizado. É nesse cenário político conturbado e permeado por contradições, que emerge uma literatura engajada, comprometida com a fomentação de uma identidade angolana capaz de preencher as fissuras de uma sociedade formada por grupos étnico-culturais diversos, necessária para a formação da nação.

Esse primeiro e importante momento na historia literária de Angola foi um período de grandes romances. Naquele momento, a forma romanesca do colonizador era traduzida para um ambiente no qual, recursos como a oralidade e a criação de neologismos ajudavam a contar a história daquele novo indivíduo que nascia carente de legitimação enquanto tal. O importantíssimo papel da literatura nesse processo é ensinado também por Williams, quando definiu o verbete nacionalista como movimentos baseados na existência de um grupo político subordinado que se identifica por uma lingua especifica ou por uma suposta comunidade racial.

A criação de um individuo angolano, tão necessária para os processos político-ideológicos do país, se deu, entretanto, no momento em que a própria forma romanesca ocidental já estava em crise. O sujeito individual, indivisivel e indispensável para a constituição da identidade nacional já sofria, no mundo ocidental, um intrincado processo de descentramento reconhecido por diversos campos do saber como a sociologia, psicanálise e lingüística, como ensina Stuart Hall (2006, p.34-46) cujas reverberações podem ser encontradas ao longo dos dez contos que compõe Filhos da Pátria.

Diferentemente da grande parte dos escritores angolanos, João Melo ainda não produziu um romance. Seu amplo trabalho no campo da literatura conta hoje com a publicação de dez livros de poesia, um de ensaios e quatro de contos. A respeito de Filhos da Pátria, a escolha da forma conto se dá pela imposição da própria matéria 
narrada. O individuo que encontramos em suas páginas é representante não de uma identidade única e homogênea, mas de múltiplas possibilidades subjetivas dentro de um país cujo processo de estruturação identitária como contraponto à dominação portuguesa já foi superado.

A expressão da subjetividade nesta obra de João Melo opera magistralmente a dupla acepção do termo que o define tanto como aquele que sofre uma ação, sendo, portanto, sujeitado, como aquele que opera a ação, sendo assim, o sujeito. Equilibrando suas estórias na tensão entre os dois pólos do mesmo termo, Melo nos brinda com uma crítica à sociedade angolana que vai muito além da vitimização do seu povo frente à barbárie colonial. Através de uma análise intimista, que examina a vida privada, sem meias palavras, compreendemos rapidamente que o algoz de Angola é, hoje, não é outro senão o próprio angolano.

Como podemos perceber no caso desta obra, o uso do conto não se dá como opção técnica que confere tintas de africanidade à forma de expressão européia, como pode vir a ser o caso no romance. O conto em Filhos da Pátria se impõe pela própria tensão inerente às contradições presentes nos fatos narrados, que, caso romanceados, perderiam imediatamente sua amplitude narrativa. Embora se considere a contextualização psicológica como prejudicial à efetividade da narrativa breve como a encontramos no conto, no caso desta obra, um narrador-personagem se coloca frente ao narrador-autor reclamando para si a legitimidade de sua "bisbilhotice" e intromissão, fazendo da própria contextualização psicológica objeto narrável, parte do extraordinário e miraculoso, necessários à amplitude narrativa, como encontramos no conto "Ngola Kiluanje" (p. 97-115). Neste caso os dois episódios nos quais o narrador-personagem interfere na estória a fim de nortear o leitor acerca da questão racial em Angola, acaba por ironizar o tipo de tratamento geralmente dado a essa questão, em torno da qual gira a estória desse angolano branco, fetiche africano de uma brasileira afrodescendente engajada no movimento negro carioca. 
O narrador onisciente intruso que permeia a maior parte das estórias não possui qualquer compromisso com a representação objetiva dos fatos, assim como o caráter ficcional é claramente anunciado em "O efeito estufa” (p. 59-72) “[...] e embora pessoalmente não tenha grandes motivos para gostar de Charles Dupret, serei obrigado (espero e confesso: com secreto gozo) a transmitir-lhes os resultados da minha investigação ficcional, se é que isso existe...", minando assim qualquer traço de confiança entre leitor e narrador, bem como de desejo de verdade. A exposição do processo composicional, como acontece ao logo de todos os contos, se anuncia como metáfora dos processos de gerência que orquestram aquela sociedade. Assim como o narrador-autor organiza seu texto, esses processos se dão de forma anunciadamente parcial e relativizada.

Atribuindo às suas estórias uma função metonímica, na medida em que tratam do macrocosmo social através de narrativas que se dão no microcosmo familiar, todos os contos de Filhos da Pátria, bem como seus conflitos, se encerram no ambiente particular das relações ou na cisão dos indivíduos. A barbárie da dor, da fome, das violências, preconceitos e desigualdades marcam profundamente as personagens em seu intimo. Em "Natasha" (p. 37-58) encontramos uma narrativa calcada no fluxo de consciência na qual as vozes dela e de seu marido se confundem ao contar uma estória de mentiras, desilusão e frustração entre a russa e o angolano. Ela, encantada pelo mundo mágico de possibilidades que ele lhe promete, pela virilidade e volúpia física que lhe proporciona, deixa sua pátria por Angola, onde encontra uma realidade de miséria, infidelidade e mentiras, o que no mundo de referências e alusões criado por Melo, poderia ser visto como a desilusão do socialismo, traído pela Angola infiel. O mesmo acontece na realização do discurso nacionalista demagógico proferido pelas elites, expresso pela estória de Charles Dupret em "O efeito estufa": um estilista de discurso nacional inflamado, que desenha roupas pretas para estrangeiros brancos e manda a filha para estudar na Inglaterra. Já a corporalidade da consciência e da ação de protesto no livro, é 
simbolizada pelos dois cavalos de "O cortejo" (p. 133-146), revoltados com a desigualdade social entre a família dos noivos que transportam e a população da cidade, resolvem, como ato de protesto, levar o casal em disparada às mais pobres e decadentes áreas de Luanda.

Assim, através da realização dos processos sociais na vida privada, somos levados a questionar o papel de agência naqueles indivíduos, seguindo por estórias nas quais a figura opressora não mais é corporalizada pelo homem branco europeu. A figura do homem branco chega inclusive a ser vitimizada como acontece com Natasha que é iludida pelo marido negro e Ngola Kiluanje que tem a família expulsa de Angola pela simples razão de serem brancos, ainda que angolanos.

Enquanto sujeitados, “Tio, mi dá só cem” (p. 27-36) e “O feto" (p. 147-156), são os únicos contos narrados totalmente em primeira pessoa. Em ambos os casos a voz é emprestada ao oprimido, sem intermediação, violentamente e em ritmo alucinante. Nos dois contos a vida dos protagonistas é destruída pela guerra e pela fome, sendo a violência a base da formação de sua estrutura de sentimento. Nessas estórias, narrados por um menino assassino e por uma menina prostituta, respectivamente, a violência é seu único meio de interação com o mundo. Escritos em forma de monólogos e endereçados a um tu que não se pronuncia, os textos parecem dirigir-se diretamente ao leitor, que é colocado na desconfortável situação de testemunha inerte, experimentado a sensação de silêncio condescendente com uma realidade revoltante, deslocando as tensões para a subjetividade do expectador.

A fragmentação do sujeito, as tensões trabalhadas no nível da subjetividade e a relativização do ponto de vista em Filhos da Pátria se constituem como indicativo que não deve ser ignorado. $\mathrm{Na}$ medida em que aponta para uma crítica da sociedade na qual se insere, percebemos, através dessa obra, a superação do discurso de afirmação nacional frente à situação colonial. Ainda que comprometida com o social, temos aqui um exemplo da literatura de um povo já amadurecido, capaz de se projetar agora para uma dimensão além do 
nacional, certamente muito mais literária e absolutamente interessante. Um passo adiante para os estudos das literaturas pós-coloniais de lingua portuguesa.

MELO, João. Filhos da pátria. Rio de Janeiro: Record, 2008 (172p.).

\section{Referências Bibliográficas}

CHAVES, Rita. A formação do romance angolano. São Paulo: Universidade de São Paulo, 1999

HALL,Stuart. A questão cultural na pós-modernidade. Rio de Janeiro: DP\&A, 2006.

WILLIAMS, Raymond. Keywords. Nova Iorque: Oxford University Press, 1985. 